\title{
The National Screening Committee Review of Diabetic Retinopathy Screening
}

Diabetic retinopathy screening is here to stay. The challenge has changed from initiating any screening to ensuring that programmes work well. Ophthalmologists need good screening programmes to ensure that patients with sightthreatening diabetic retinopathy receive timely care, but also importantly good screening should reduce time-wasting false positive referrals and needless patient worry. There is inconsistency in diabetic retinopathy screening in the UK, ranging from systematic programmes employing the latest cost-effective technology and recording outcomes, to ad hoc services with no central organisation and no recording of service outcomes. ${ }^{1}$ The proportion of people with known diabetes screened in a year ranges from $38 \%$ to $85 \%$ across districts, and from $14 \%$ to $97 \%$ across practices. ${ }^{2}$

Lessons can be learnt from other diseasescreening programmes. Quality failures in cervical cancer screening in the early 1990s were studied in detail and led to the formation in 1996 of the National Screening Committee (NSC). The role of the NSC is to evaluate new and existing programmes and recommend their development or termination. Over 300 screening programmes have been identified; some are of dubious benefit, and many would benefit from more coherent and consistent implementation. In ophthalmology, concerns were expressed about preschool vision screening and this has in turn influenced health authority thinking. ${ }^{3}$ The decision of the NSC to look at diabetic retinopathy screening was therefore of major significance for ophthalmologists. Following the review there are now clear recommendations that will allow ophthalmologists and health commissioners to assess local programmes and identify gaps and weaknesses. $^{4}$

Experience from screening in other conditions shows common elements in effective programmes. A quality assurance system should be central to each programme, incorporating three essential elements: explicit quality standards, an information system that allows performance to be compared with standards, and managerial authority to take action if quality is failing or not improving fast enough. ${ }^{5}$ It follows that the acquisition of a hard record for performance monitoring is critical. We already know from our normal clinical practice the importance of a named accountable lead and defined individual responsibilities. In addition, screening programmes should integrate treatment because the gains from early asymptomatic detection can be wasted, for example, if there are long treatment waiting lists. Integrated, simple, acceptable care in a community setting is particularly important for diabetic retinopathy where the term 'screening' is a convenient administrative shorthand for a delegated part of normal patient care.

The NSC review consulted widely and eventually made specific recommendations for diabetic retinopathy screening. First, the aim of screening is the detection of treatable sightthreatening diabetic retinopathy, although the detection of any retinopathy may be a secondary benefit. Secondly, screening by direct ophthalmoscopy using a hand-held ophthalmoscope does not give adequate specificity and sensitivity, and should be abandoned for systematic screening, although of course it remains a useful technique in the clinic. Thirdly, indirect ophthalmoscopy using a slit-lamp is sensitive and specific enough to be viable, and widespread availability in high street optometrists is an advantage, but the method requires considerable skill and quality assurance is difficult to achieve. Fourthly, camera-based screening is the preferred option for screening, carrying the principal advantage of an image record, for patient education, review of disease progression, and quality assurance. Digital cameras are becoming both better and cheaper and the image is satisfactory for screening purposes. With appropriate training and equipment different professional groups might participate in programme delivery, based on local decisions. Fifthly, the costs and benefits of the preferred option were assessed and the NSC now recommends the establishment of a national programme of community-based digital retinal photography.

Health authorities are advised to take account of the NSC's recommendations in making decisions on investment in equipment
Mr. J.T. Gillow, MRCP, FRCOphth $\square$ Department of Ophthalmology North Staffordshire Hospital Stoke-on-Trent ST4 7LN, UK

Dr J.A. Muir Gray, CBE, MD, FRCP(Glas\&Lond)

Joint-Director, UK National Screening Committee Institute of Health Old Road

Oxford OX3 7LF, UK 
and staff training, in order to provide a more evidencebased service. Practical advice on setting up a systematic diabetic retinopathy screening programme can be found at http://www.nelh.nhs.uk/screening/diabeticretinopathy/. The NSC has recommended to Ministers that a national diabetic retinopathy screening programme using community-based digital retinal photography would represent money well spent. The NSC has costed the extra resources involved in systematic screening and the associated additional medical costs of managing both true and false positive cases. Total pump priming funds of $£ 67$ million over 4 years will be required in England, but by year 4 it should be possible to fund the programme from revenue savings from reduced treatment costs in the NHS. The rationale for a systematic programme is enhanced further when account is taken of the wider economic and social costs of visual impairment. ${ }^{6}$

Whether this simple, consistent and cost-effective programme will be implemented in England will not be known until the Diabetes National Service Framework is published in spring 2001. However, it is likely that at least one Celtic nation will implement the NSC recommendations, setting an example for others to follow.

\section{References}

1. Bagga P, Verma D, Walton C, Masson EA, Hepburn DA. Survey of diabetic retinopathy screening services in England and Wales. Diabet Med 1988;15:780-2.

2. Grimshaw GM, Baker R, Wilson AD, Thompson JR, Atkinson M. Report of the Inter-College Audit of Diabetic Retinopathy Screening. Clinical Governance Research and Development Unit, University of Leicester, 1999.

3. Snowdon SK, Stewart-Brown SL. Preschool vision screening. Health Technol Assessment 1997;1(8).

4. Garvican L, Clowes J, Gillow T. Preservation of sight in diabetes: developing a national risk reduction programme. Diabet Med 2000;17:627-34.

5. National Screening Committee. First Report of the National Screening Committee. Health Departments of the United Kingdom, April 1998.

6. Javitt JC, Aiello LP, Chiang Y, Ferris FL, Canner JK, Greenfield A. Preventative eye care in people with diabetes is cost-saving to the federal government: implications for health care reform. Diabetes Care 1994;17:909-17. 